\title{
Not so radiant anymore
}

\author{
Following the Fukushima disaster nuclear energy has an uncertain future at best. But whether we can \\ really afford to abandon nuclear power remains an open question.
}

The tragedy that struck the Fukushima Daiichi nuclear plant on 11 March this year has displaced tens of thousands of local residents and released significant amounts of radiation into the environment. The reactors are still not cooled down to a stable state, and the clean-up of the site is envisioned to take many years, especially as in some of the reactors the radioactive fuel appears to have melted through its surrounding steel container.

Not unsurprisingly, the accident has led to a widespread public condemnation of nuclear energy. Countries such as Germany and Switzerland have declared their withdrawal from nuclear energy altogether, while Italian voters have reaffirmed the country's non-nuclear status in a referendum. It seems unlikely that recent efforts to build new nuclear power stations in the US and the UK will proceed anytime soon.

Where does that leave commercial nuclear power? The Fukushima disaster clearly has revealed plenty of shortcomings, especially in the design of the plant's reactors. These were all constructed between 1967 and 1979. Being generation II reactors, their operation is crucially dependent on the water needed to constantly cool the reactor cores. As is well established now, this has been a key weakness following the Tohoku earthquake, when electrical power at the Fukushima Daiichi plant failed. As planned, the diesel back-up generators started up and cooled the reactors - but only until the tsunami arrived and knocked out the generators.

Unfortunately, a historic design wasn't the only problem. The Fukushima Daiichi reactors (and others, too) are built at a place where they never should have been - in an active earthquake zone, right at the sea and thus exposed to tsunamis. All this is not knowledge gained in hindsight, but was commonly known to industry experts before the earthquake.

In light of these shortcomings the pressure to shut down unsafe nuclear plants in seismically active regions is understandable. But what are the possible alternatives?

In Germany, the present plan is to shut down all nuclear reactors by 2022 . Before the Fukushima disaster, nuclear energy accounted for about $23 \%$ of Germany's

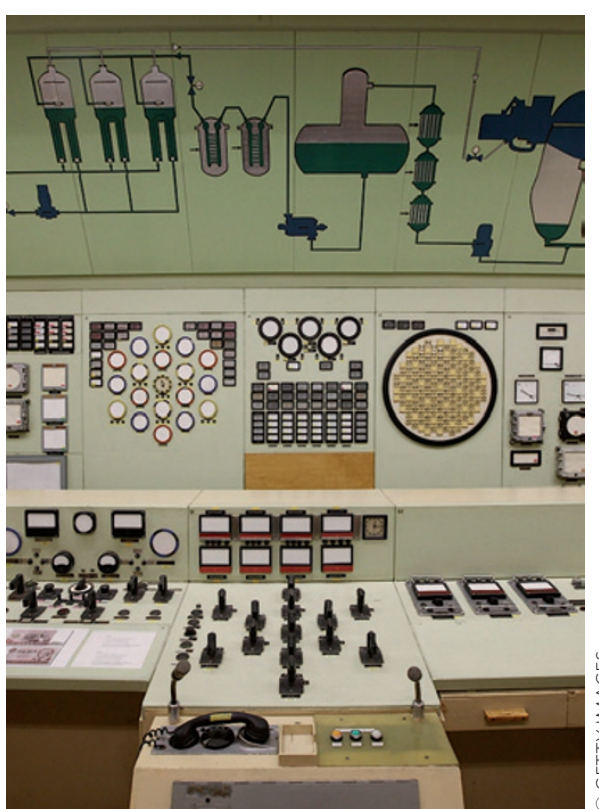

For this reason nuclear energy might still be an alternative. It is important to re-iterate that the Fukushima Daiichi plant consists of technology that is more than 40 years old and bears little comparison with modern designs. The latest generation III power plants, for example, do not require active cooling but are entirely passive. Even without human intervention or electricity supply these reactors can cool down on their own, as long as structural integrity is maintained. Yet, these technologies do not solve the issue of nuclear waste disposal, for which potential alternatives exist. So-called breeder reactors are able to use a much larger fraction of the energy contained in nuclear fuel rods. At present only a few per cent of the available radioactivity in a fuel rod is burnt. Reprocessing can reclaim most of the remaining radioactivity, but breeder technology is even better as these reactors add more usable radioactive isotopes to the fuel than they consume. China and other countries are currently pursuing breeder technology.

Many fundamental mistakes were made at the Fukushima plants. Old reactor designs were kept running in a dangerous earthquake zone. Known risks were not acted on. The reporting of facts by the plant operator Tepco has seen scandalous delays. There is little in this mix to appease public opinion.

In light of such short-sighted yet far-reaching political decisions, it seems doubtful that there is any hope for a rational debate on the pros and cons of nuclear energy. This is regrettable. As a society we are facing some of the most fundamental challenges in the way we create and use energy in a clean and sustainable manner. The alternative to nuclear energy cannot be, even temporarily, to rely on carbon dioxide-heavy emitters. Instead, we need to intensify our efforts to use renewable energy. However, it is also clear that such efforts can not replace nuclear and carbon-based energy sources at the same time. The question is then whether under some circumstances nuclear technology may be an acceptable alternative. Therefore, what is needed is a fact-based debate, rather than superficial arguments. The issue of our future energy supply is far too important to be conducted as a guessing game. 